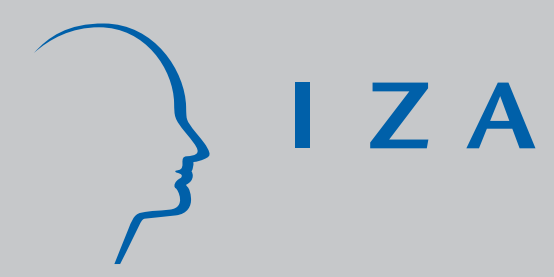

IZA DP No. 1843

Women and Competition in Elimination Tournaments:

Evidence from Professional Tennis Data

Thierry Lallemand

Robert Plasman

François Rycx

November 2005 


\title{
Women and Competition in Elimination Tournaments: Evidence from Professional Tennis Data
}

\author{
Thierry Lallemand \\ Free University of Brussels, DULBEA and CPC \\ Robert Plasman \\ Free University of Brussels, DULBEA \\ François Rycx \\ Free University of Brussels, DULBEA \\ and IZA Bonn
}

Discussion Paper No. 1843

November 2005

\author{
IZA \\ P.O. Box 7240 \\ 53072 Bonn \\ Germany \\ Phone: +49-228-3894-0 \\ Fax: +49-228-3894-180 \\ Email: iza@iza.org
}

\begin{abstract}
Any opinions expressed here are those of the author(s) and not those of the institute. Research disseminated by IZA may include views on policy, but the institute itself takes no institutional policy positions.

The Institute for the Study of Labor (IZA) in Bonn is a local and virtual international research center and a place of communication between science, politics and business. IZA is an independent nonprofit company supported by Deutsche Post World Net. The center is associated with the University of Bonn and offers a stimulating research environment through its research networks, research support, and visitors and doctoral programs. IZA engages in (i) original and internationally competitive research in all fields of labor economics, (ii) development of policy concepts, and (iii) dissemination of research results and concepts to the interested public.
\end{abstract}

IZA Discussion Papers often represent preliminary work and are circulated to encourage discussion. Citation of such a paper should account for its provisional character. A revised version may be available directly from the author. 
IZA Discussion Paper No. 1843

November 2005

\section{ABSTRACT}

\section{Women and Competition in Elimination Tournaments: Evidence from Professional Tennis Data}

This paper examines how professional female tennisplayers react to: i) prize incentives and ii) heterogeneity in ex ante players' abilities. It is found that a larger prize spread encourages women to increase effort, even when controlling for many tournament and player characteristics. Further results indicate that uneven contests lead favourites to win more games and underdogs to be less performing. They also show that the performance differential between players increases with the ranking differential. These findings suggest that the outcome of a match is more linked to players' abilities than to players' incentives to adjust effort according to success chances.

JEL Classification: J33, J41, M12

Keywords: $\quad$ sports economics, tournaments, incentives, performance, women

Corresponding author:

François Rycx

Université Libre de Bruxelles

CP 140 - Av. F.D. Roosevelt 50

1050 Brussels

Belgium

Email: frycx@ulb.ac.be 


\section{INTRODUCTION}

In this paper, we use a unique data set, collected from the website of the Women's Tennis Association (WTA), to assess how professional female tennisplayers react to: i) prize incentives and ii) heterogeneity in ex ante players' abilities. ${ }^{1}$ Tennis data offer several advantages for the analysis of tournament models (Sunde, 2003). Firstly, the number of players is restricted to two and the rules of the game are common knowledge. Therefore, players have less opportunity to adopt strategies to deviate from the optimal level of effort (e.g. coalition, sabotage, doping). Secondly, the pre-determined structure of prizes rules out the endogeneity problem of rewards. Thirdly, there is no information asymmetry among contestants. Both players can infer precise measures of their respective strength before any match (e.g. through their current world ranking and previous head-to-head matches). A final advantage is that the number of contests in tennis tournaments is limited. In other words, the horizon of the game is finite. Hence, the problem of repeated contests (i.e. the expectation of winning an additional prize at some future moment in time), which is frequently encountered within firms and which is not observable to the econometrician, is avoided.

According to the theoretical literature, players' effort in individualistic sports (e.g. golf, tennis, foot races) depends mainly upon the structure of prizes and the heterogeneity in players' abilities. Tournament models suggest that the implementation of a differentiated prize structure, where the largest prize is awarded to the best contestant, increases the player's average level of effort and performance (Lazear and Rosen, 1981). For elimination tournaments with a finite number of contestants, it is argued that the optimal prize structure should include an extra reward in the final stage so as to make sure that the players maximise their effort (Rosen, 1986).

Relatively little attention has been given to gender differences in the optimal prize structure. However, several theories suggest that women and men might react differently to prize incentives. Following the psychology literature, this may be due to the fact that women are stigmatised individuals who either internalize negative stereotypes with respect to men (Greenwald and Banaji, 1995) or feel threatened by such stereotypes and thus disengage from situations where their self-esteem could be damaged (Steele, 1997). It is also argued that women might be more averse to competition because they supposedly are: i) less socio-

\footnotetext{
${ }^{1}$ Following Szymanski (2003) individualistic sports (e.g. golf, tennis, foot races) represent an ideal setting to determine the prize structure that maximizes agents' performance.
} 
biologically suited to compete (Knight, 2002), and/or ii) more altruistic and concerned with equal payoffs (Eckel and Grossman, 1998). ${ }^{2}$

Apart from prizes, the final outcome of a contest may also depend on heterogeneity in the ex ante strength of players. However, there is no theoretical consensus on whether the players' performance should increase or decrease with the diversity in players' abilities (Lazear and Rosen, 1981; Rosen, 1986; Prendergast, 1999; Sunde, 2003). The incentive hypothesis suggests that both players are encouraged to put forth less effort in highly uneven matches since they have unequal chances of winning. In contrast, the capability hypothesis stresses that larger heterogeneity, ceteris paribus, leads to the favourite performing better and the underdog winning fewer games since his inferior ability reduces his probability of winning. The difference with the incentive hypothesis is that underdogs are performing less because of their weaker ability or talent, not because they are less motivated to put forth higher effort.

Empirical studies on the determinants of players' performance are not very numerous. They generally support the idea of a positive incentive effect of prizes and/or prize spread (e.g. Ehrenberg and Bognanno, 1990a,b; Fernie and Metcalf, 1999; Frick and Prinz, 2002; Maloney and McCormick, 2000). However, some papers obtain evidence in favour of sorting rather than incentive effects (e.g. Lynch and Zax, 1998, 2000). ${ }^{3}$ As far as we know, Sunde (2003) is the only one to focus simultaneously on the impact of prizes and players' heterogeneity in uneven contests. The author uses professional tennis data for men (ATP) and finds that larger prizes foster individual as well as aggregate effort during a match, even when controlling for players' characteristics and a number of tournament dummies. He also shows that the incentive effect of heterogeneity is greater than the capability effect.

To our knowledge, the only evidence as regards the reaction of women to prize incentives in an individualistic sport has been provided by Frick and Prinz (2002). Using data on city marathons, the authors show that average finish times of both men and women fall when the prize spread increases. However, women are found not to respond to additional rewards for absolute performance while men do. The hypothesis that men and women react differently to competitive incentive schemes has also been tested in two experimental studies.

\footnotetext{
${ }^{2}$ However, several studies find that men are more cooperative than women (Brown-Kruse and Hummels, 1993) but no significant gender differences in altruism are obtained (Bolton and Katok, 1995).

${ }^{3}$ For other studies regarding the incentive effects of tournament theory see e.g. Abrevaya (2002) and Bognanno (1990) for US professional bowling, Becker and Huselid (1992) and Von Allmen (2001) for NASCAR, Terkun and Maloney (2000) for motorcycle and Orzag (1994) for the PGA Tour.
} 
Gneezy et al. (2003) suggest on the basis of a maze experiment that women's and men's performance increase equally in single sex tournaments due to competition. In mixed gender tournaments results are quite different. Indeed, men's performance increases significantly, while that of women remains unchanged. These findings suggest that women do not dislike competition per se, but dislike competition with men. ${ }^{4}$ The field study conducted by Gneezy and Rustichini (2004), with children running on a track, ends up with somewhat different results. Indeed, it is found that competition has a very weak impact on girls' performance even in single sex races. Hence, it remains unclear whether men and women react differently to prize incentives in single sex tournaments.

The present paper contributes to this literature by examining how professional female tennisplayers react to: i) prize incentives and ii) ex ante heterogeneity in players' abilities. To do so, we use a unique data set containing information on the two final rounds of all tennis tournaments organized by the WTA between the years 2002 and 2004 (i.e. Grand Slams and final of WTA championships, Tier I, Tier II, Tier III, Tier IV and Tier V). Our data set provides detailed information on players (e.g. age, experience, ranking, status during the tournament, number of previous head-to-head matches won and lost against the opponent before the match, number of titles won before the tournament, number of games played in the tournament before the match) and tournaments (e.g. type of tournament, size, prize and ranking-points structure, soil of the court, outdoor or indoor tournament, month, year). It includes information on 502 matches or 1,004 observations for individual players.

Our methodology is inspired by Sunde (2003). As an indicator of heterogeneity in the strength of contestants we use the difference in their WTA ranks. In order to control for the pyramid structure of players' quality, we rely on the indicator built by Klaassen and Magnus (2003). The prize spread is measured by the difference of prizes between winning and losing a match. In semi-finals, we consider the option value of winning the tournament. As a sensitivity test, this option value is weighted by the ability of potential contestants in the final. The performance of a player is measured by the individual number of games won at the end of a match. The existence of a potential selection bias is addressed with Heckman's (1979) two-step estimation procedure.

To the best of our knowledge, this paper is the first with Frick and Prinz (2002) to test tournament models for women in professional individualistic sports. Empirical findings

\footnotetext{
${ }^{4}$ This conclusion seems to be driven by the fact that women feel that they are less competent than men beyond what would be warranted by the small advantage of the latter in the maze experiment.
} 
support the existence of a positive and significant relationship between prize spread and women's performance. ${ }^{5}$ These findings are robust to the inclusion of many control variables and to the addition of players' fixed effects. Similar results have been obtained by Sunde (2003) for men. Hence, it appears that both sexes react positively to prize incentives in professional single sex tournaments. Further results for women indicate that uneven contests lead favourites to win more games and underdogs to be less performing. They also show that the difference between the number of games won by the favourite and the underdog increases with the ranking differential between the players. These findings support the capability effect of heterogeneity on players' performance. In other words, they show that the final outcome of a match is more linked to players' abilities (and intrinsic talent) than to players' incentives to adjust their effort according to their success chances. Sunde (2003) found the opposite result for men. He suggests that the incentive effect of heterogeneity is greater than the capability effect. A potential explanation for this dissimilarity is that differences in rankings between players more accurately reflect heterogeneity in the abilities of women than in those of men.

The remainder of this paper is organized as follows. Section 2 describes the methodology and data set. Section 3 presents the empirical results and robustness tests. The last section concludes.

\section{Methodology AND Data}

\subsection{Methodology}

To test the incentive effect of prizes and to assess the impact of players' heterogeneity on individual performance, we follow an estimation strategy that is quite similar to that of Sunde (2003). This strategy is based mainly on the estimation of the following equation:

$$
E_{i m j}=\beta_{0}+\beta_{1} P_{m j}+\beta_{2} H_{m j}+\beta_{3} X_{i j}+\beta_{4} Y_{j}+\varepsilon_{i m j}
$$

where $E_{i m j}$ is the individual performance of player $i$ in match $m$ of tournament $j$. The performance of a player is measured by the individual number of games won at the end of a match. $P_{m j}$ is the prize spread in match $m$ of tournament $j$. It is measured as the differential of

\footnotetext{
${ }^{5}$ However, results indicate that the performance of underdogs (i.e. players with a disadvantage ex ante) is not sensitive to the magnitude of the prize spread.
} 
prizes between winning and losing a match. In semi-finals, players may hope to increase their earnings by playing the final match of the tournament. To account for this option value of further prizes, we compute the difference between the prizes for winning the tournament and winning the semi-final. This amount is added to the prize spread between winning and losing the semi-final. Since the value of the continuation option depends on: i) the quality of the player, ii) the strength of the opponent in the semi-final and iii) the ability of the future potential opponent in the final, two other measures for the prize spread are considered. On the one hand, we weigh the option value for each semi-finalist by the relative strength of the two contestants in the other semi-final. ${ }^{6}$ On the other hand, because there is a higher probability to meet in the final the strongest contestant involved in the other semi-final, we weigh the value of the continuation option by the ability of the better-ranked player. $H_{m j}$ indicates the level of heterogeneity in the strength of players in match $m$ of tournament $j$. We rely on the official ranking published by the WTA before the tournament to infer information on the relative strength of players. By taking the difference between a player's own rank and her opponent's rank, we obtain an up-to-date measure of the ability of each player ex ante. In tennis, smaller ranks are associated with better players. Hence, the value of heterogeneity is negative for favourites (i.e. ex ante better ranked players) and positive for underdogs (i.e. ex ante weaker players). To test the hypothesis of a hump-shaped relationship between heterogeneity and players' performance, we add alternatively the squared rank differential and 5 dummies indicating the magnitude of heterogeneity. $X_{i j}$ is a set of player control variables including age, share of the player's wins in previous head-to-head matches, number of previous games played before the match, number of titles won in the year before the tournament, status of the player in the tournament, and a dummy variable indicating whether the individual is playing a final. $Y_{j}$ is a set of tournament characteristics including surface (1 dummy), outdoor or indoor court ( 1 dummy), total prize money of tournament, tournament size (i.e. number of players enrolled in the tournament), tournament type (i.e. Grand Slams and final of WTA championships, Tier I, Tier II, Tier III, Tier IV and Tier V), month (9 dummies), and year (2 dummies). We use pooled OLS estimators but we also rely on panel data models in order to control for unobserved and time invariant heterogeneity between players (e.g. confidence,

\footnotetext{
${ }^{6} \mathrm{We}$ assign a particular number to both potential opponents playing the other semi-final. A stronger opponent gets a number between 0.1 and 0.5 (since his probability to win the final is high) and a less able opponent gets a number between 0.6 and 1 (since his probability to win the final is weak). Next, we take the average of these numbers to weigh the option value of each player in semi-final.
} 
concentration, refocusing after errors, enjoyment, relaxed attitude, technical features). Fixed effects models may be appropriate since all players qualified for the semi-finals and finals of WTA tournaments between 2002 and 2004 are included in the sample. Moreover, as individual player effects may be random due to unobserved or unknown factors influencing players' performance, we also use random effects models.

To distinguish between the capability and incentive effects of heterogeneity on a player's performance, we also estimate the following equation:

$$
\Delta_{m j}=\beta_{0}+\beta_{1} P_{m j}+\beta_{2} H_{m j}+\beta_{3} X_{m j}+\beta_{4} Y_{j}+\varepsilon_{m j}
$$

where $\Delta_{m j}$ is the difference between the number of games won by the favourite and the underdog in match $m$ of tournament $j{ }^{7} H_{m j}$ is the absolute difference in the rankings of both players in match $m$ of tournament $j . X_{m j}$ is a vector measuring the differences between the characteristics of the favourite and the underdog in match $m$ of tournament $j$ (w.r.t. age, wins in previous head-to-head matches, number of titles won during the preceding year, number of games played before the match). $P_{m j}$ is the average prize differential in match $m$ of tournament $j . Y_{j}$ is defined as in equation (1).

\subsection{Data}

Our empirical analysis is based on a unique data set collected from the website of the WTA (http://www.wtatour.com). It contains information on all professional female tennisplayers who participated in at least one of the two final rounds of an official WTA tournament between 2002 and 2004. Six types of tournaments are considered: Grand Slams and final of WTA championships, Tier I, Tier II, Tier III, Tier IV and Tier V. Unfortunately, we had to drop out 28 matches either because they ended before the rules could indicate a winner (e.g. due to a player's injury) or because we were unable to collect all required information (e.g. the prize structure of the Australian Open in 2002 is not available). After eliminating these

\footnotetext{
${ }^{7} \Delta_{m j}$ is generally expected to be positive because the favourite is most likely to perform better and to win the match.
} 
matches we end up with a final sample of 1,004 observations for individuals playing in 502 matches.

[Take in Table 1]

Table 1 depicts the means and standard deviations of selected variables. We note that on average each player wins around 11 games per match, favourites perform better than underdogs (11.9 vs. 10.3 games won), and the ranking differential between two contestants is around 31 . We also find that the average prize spread between winning and losing a match amounts to $73,920 \$$ in finals and to $111,610 \$$ in semi-finals (including the option value of winning the final). ${ }^{8}$ Finally, Table 1 shows that professional female tennisplayers included in our sample: i) are on average 23 years old, ii) have already played each other 3 times and iii) are generally seeded players.

\section{EMPIRICAL RESULTS}

\subsection{Prize and heterogeneity effects}

[Take in Table 2]

Table $2 A$ reports the OLS estimates with White (1980) heteroscedasticity consistent standard errors of the effects of prize spread and heterogeneity on the individual number of games won by players. Controlling for a large number of player and tournament characteristics, we find that all prize spread indicators have a positive and significant impact on players' performance. Indeed, findings show that a doubling of the prize differential increases players' performance by between 0.8 and 1.2 games ceteris paribus. This result is in line with tournament theory which suggests that players perform better when financial rewards are higher. Another interesting result concerns the impact of heterogeneity in players' abilities on individual performance. Table $2 \mathrm{~A}$ shows that regression coefficients associated with ranking differentials between players are always negative and significant. This means that the number of games won per match by a player depends positively (negatively) on the size of his ex ante ranking

\footnotetext{
${ }^{8}$ All prizes in euros and in pounds are converted in US dollars using the exchange rate prevailing at the beginning of the tournament. All prizes are deflated by the 2004 CPI.
} 
advantage (disadvantage). Finally, the control variables show, inter alia, that players win more games on clay courts and when they have won more head-to-head matches than their opponents (see Table Al in the Appendix).

Table $2 B$ presents the effects of prizes and heterogeneity on players' performance using both fixed and random effects with White (1980) heteroscedasticity standard errors. ${ }^{9}$ Results indicate that the inclusion of players' fixed effects improves the explanatory power of our model (the adjusted $\mathrm{R}^{2}$ rises to 0.15 ). We also find that the impact of prizes on performance remains positive and significant, but only when the value of the continuation option is not weighted by the strength of future players (see Model A of Table 2B). Overall results suggest that a player's performance is driven by the incentive effects of financial rewards rather than by sorting (or self-selection) effects. Also noteworthy is that the inclusion of players' fixed effects leaves the sign, magnitude and significance of the heterogeneity coefficient unaffected.

\subsection{Heterogeneity: incentive or capability effect?}

So far, we focused on all players regardless their status. Therefore, we were not able to distinguish between the capability and incentive hypotheses regarding the effect of heterogeneity on a player's performance. The incentive hypothesis suggests that both players are encouraged to put forth less effort in highly uneven matches since they have unequal chances of winning. In contrast, the capability hypothesis stresses that, ceteris paribus, larger heterogeneity leads to the favourite performing better and the underdog winning fewer games since his inferior ability reduces his probability of winning. In this section, we try to discriminate between both hypotheses by examining the performance of favourites and underdogs separately.

A simple way to establish whether a player is a favourite or an underdog is to compare his position in the WTA ranking with that of his opponent. Indeed, the favourite may be seen as the player with the highest rank before the match. However, players may also rely on previous head-to-head matches to assess their probability of winning. Indeed, a player who won most of his previous head-to-head matches with a particular opponent has a higher probability to win the next match against the same player. In this section, we consider the

\footnotetext{
${ }^{9}$ Statistical tests reported in Table $2 B$ show that we may reject the null hypotheses that fixed effects are not significantly different. Moreover, the Breusch-Pagan LM test indicates that the probability to be wrong in accepting the existence of random effects is very high (above 75\%). Therefore, fixed effects may be preferred.
} 
individual with the highest share of wins over his contestant as the favourite player. If both contestants won the same number of head-to-head matches or if they never played against each other, the favourite is the player who is better ranked. ${ }^{10}$

[Take in Table $3 A$ and $3 B$ ]

Tables $3 A$ and $3 B$ show how the performance of favourites and underdogs is influenced by prize incentives and the diversity in players' strength. Results indicate that the number of games won by favourites depends positively and significantly on the prize spread, even when controlling for a large number of variables including players' fixed effects. ${ }^{11}$ In contrast, it is found that the performance of underdogs is not significantly affected by the size of the prize spread. Further results show that heterogeneity in players' abilities has a negative and significant impact on the number of games won by both types of players. To put it differently, they suggest that: i) underdogs win fewer games when their opponents are stronger (i.e. the average performance of an underdog is reduced by 0.3 games when the ranking differential doubles), and ii) the number of games won by favourites is positively related to their ex ante advantage (i.e. the average performance of a favourite is increased by 0.25 games when the ranking differential doubles). These findings are more in line with the capability hypothesis than with the incentive argument. Indeed, the latter suggests that both players reduce their effort and perform less well in uneven contests. However, our findings show that uneven matches lead favourites to win more games and underdogs to be less performing. As a result, it appears that the lower performance of underdogs in uneven matches is driven by their inferior ability (and intrinsic talent) rather than by their reduced effort.

\footnotetext{
${ }^{10}$ There are 136 matches in our sample involving opponents that have never played against each other and 43 matches where players have the same number of head-to-head wins.

${ }^{11}$ Individual fixed effects are significantly different for favourites and underdogs (at the 1 and $15 \%$ level, respectively). However, the p-value associated to the Breusch and Pagan lagrangier multiplier test indicates that the probability to be wrong in accepting the existence of random effects is at least $80 \%$ (for both types of players). Therefore, fixed effects may be preferred. See Table A2 in the Appendix for a comparison of random and fixed effects.
} 


\subsection{Robustness tests}

[Take in Table 4]

To test the robustness of this interpretation, we use the difference in the number of games won by the favourite and the underdog per match as dependent variable (see Equation (2)). The point is that the capability hypothesis suggests that a tennis match is shorter and its final outcome clearer when heterogeneity in players' abilities is larger. Results presented in Table 4 show that a bigger ranking differential between players (measured in absolute value) generates a larger gap between the number of games won by the favourite and the underdog. ${ }^{12}$ More precisely, they indicate that following a $100 \%$ rise in heterogeneity, the average performance differential between the favourite and the underdog increases by around 0.55 games. ${ }^{13}$ These findings provide additional evidence in favour of the capability effect.

Another way to distinguish between the incentive and capability hypotheses is to examine the informational content of rankings. The point is that rankings do not necessarily contain the same information for all players. Individuals who played against each other several times in the past have a good knowledge of their respective style of play. For such players, rankings may provide valuable information as they can rely on them to assess their opponent's current play and adjust their effort accordingly. The informational content of rankings may be more limited for players who have almost never met before. Indeed, players who hardly know each other may be more reluctant to adjust their effort according to rankings. All in all, we may discriminate between the incentive and capability hypotheses by examining whether the effect of heterogeneity on players' performance depends on their degree of common experience. According to the incentive hypothesis, rankings' differentials should have a larger negative impact on the performance of players knowing each other well. In contrast, the capability hypothesis predicts a similar effect for both groups of players.

\footnotetext{
${ }^{12}$ Note that a similar result is found when the favourite is defined as the player with the better ranking (see Table A3 in the Appendix).

${ }^{13}$ When the favourite is defined as the player with the better ranking (see Table A3 in the Appendix), we find evidence in favour of a hump-shaped relationship between heterogeneity and differences in players' performances. The impact of heterogeneity on the difference in the number of games won by favourites and underdogs becomes negative when the absolute difference in players' ranks is around 250 (i.e. close to its maximum).
} 


\section{[Take in Table 5]}

To examine this issue, we split our sample into two categories of matches. The first category only involves players knowing each other well (i.e. with at least three previous head-to-head matches). It contains 396 individuals playing 198 matches. The second category regroups players with a small common experience (i.e. with a maximum of two previous meetings). This category includes 608 observations for individuals playing in 304 matches. Controlling for several match and tournament characteristics, Table 5 shows that the differential in players' rankings has a negative effect on the performance of both groups of players. The magnitude of this effect appears to be larger (in absolute value) for players knowing each other well. However, regression coefficients are not statistically different for both groups of players. ${ }^{14}$ These results are more in line with the capability hypothesis. They thus suggest that the final outcome of a match is more linked to players' abilities than to players' incentives to adjust effort according to their success chances.

Another argument that can be made is that our heterogeneity measure (i.e. differences in WTA ranks) is not perfectly suited to reflect ability differences among players. Indeed, Klaassen and Magnus $(2001,2003)$ note that the difference in ability among the top two players in the WTA ranking is probably larger than between the players ranked 100 and 101 since quality in tennis exhibits a pyramid structure. Hence, the authors build a heterogeneity indicator which accounts for the round of the tournament in which a player is expected to lose. However, a problem with this measure is that it does not distinguish between players who are expected to lose in the same round (e.g. players ranked between 9 and 16 are all supposed to lose in the fourth round in a Grand Slam tournament). Therefore, they suggest to apply the following logarithmic transformation to the linear ranks:

$$
R_{i j}=x_{j}-\log _{2}\left(\operatorname{Rank}_{i}\right)
$$

In this expression $R_{i j}$ measures the strength of player $i$ in tournament $j, x_{j}$ is the maximum number of rounds in tournament $j$, and $\operatorname{Rank}_{i}$ is the WTA rank of player $i$. The value of $x_{j}$

\footnotetext{
${ }^{14}$ Except when we include players' fixed effects (at the $10 \%$ level). Yet, the difference in coefficients is not significant with random effects estimators (see Table A4 in the Appendix). Also noteworthy is that fixed and random effects are not highly significant. Therefore, panel data estimators must be interpreted with caution.
} 
increases with the size of the tournament ${ }^{15}$ and the value of $R_{i j}$ is larger for better ranked players that are expected to win more matches in tournament $j$. Heterogeneity between players $i$ and $g$ in match $m$ of tournament $j\left(H_{m j}\right)$ is measured by the difference between $R_{i j}$ and $R_{g j}$. A positive value for $H_{m j}$ implies that player $i$ has an ex ante advantage over player $g$ in match $m$ of tournament $j .{ }^{16}$

[Take in Table 6]

Regressing this new heterogeneity measure, instead of differences in ranks, on the individual number of games won leads to identical results as the ones obtained previously. Indeed, Table 6 indicates that a positive and significant coefficient is associated to the Klaassen and Magnus indicator of heterogeneity. In this respect, results are thus quite robust.

So far, we focused only on financial incentives through prize money differentials. However, prizes may also be expressed in terms of ranking-points. Indeed, we may expect players to increase effort when they can win a large amount of WTA ranking-points. To test whether the perspective of winning additional places in the overall ranking encourages players to perform better, we build three indicators measuring the difference in ranking-points between winning and losing a match. As we did for the prize money differential, we add the option value of winning further ranking-points when an individual is playing a semi-final. We also consider that the probability to get the option value is not the same for all players in semi-finals. Table A5 in the Appendix shows that the coefficients associated with the rankingpoints differential are positive but generally not significant. ${ }^{17}$ Results thus suggest that players do not produce more effort when the number of ranking-points that can be gained is larger. Yet, caution is necessary because when the prize spread is interacted with the ranking-points differential (see Table A6 in the Appendix), regression coefficients become highly significant even when we control for players' fixed effects.

\footnotetext{
${ }^{15}$ The value of $x$ (i.e. the number of rounds) is respectively equal to 8 in tournaments with at least 96 contestants (e.g. Grand Slams), 7 in tournaments with between 56 and 95 contestants, 6 in tournaments with between 28 and 55 contestants, and 5 in tournaments with less than 28 contestants.

${ }^{16}$ Note that when heterogeneity is measured by differences in players' WTA ranks, a positive value for $H_{m j}$ means that player $i$ has a disadvantage ex ante with respect to player $g$ in match $m$ of tournament $j$.

${ }^{17}$ Except when: i) the option value is weighted by the strength of future contestants and ii) no individual fixed effects are included.
} 
The existence of a potential selection bias is another important issue that has to be investigated. The point is that we observe the effort in final matches only for players that have won in semi-finals. In other words, there is a censoring problem and errors might be correlated between finals and semi-finals. To examine this issue, we firstly estimate our model only for players in final matches. This yields similar results for heterogeneity in players' abilities but not for the prize spread. Indeed, regression coefficients associated with the prize differential become non significant (see Table A7 in the Appendix). However, this might be due to the fact that the variance in prizes across tournaments and time is lower when we focus on finals only.

[Take in Table 7]

Secondly, we address the potential problem of selection bias with Heckman's (1979) two-step estimation procedure. Our selection equation includes as main explanatory variables heterogeneity of players in semi-finals and the option value of additional prizes (i.e. the difference in prizes between winning the semi-final and winning the tournament). In the regression of individual performance on heterogeneity and prize spread for finalists, we add the inverse Mill's ratio obtained from the selection equation. In the first and second step equations, we also control for player, match and tournament characteristics. Table 7 shows that the effect of the inverse Mill's ratio is positive and significant. Yet, the regression coefficient associated with heterogeneity remains similar to the unconditional estimate obtained from the regression for finals only. In sum, a selection problem seems to exist but it does not appear to bias our results.

\section{CONCLUSION}

This paper examines, on the basis of a unique data set, how professional female tennisplayers react to: i) prize incentives and ii) ex ante heterogeneity in players' abilities. The data set, collected from the website of the WTA, covers all professional female tennisplayers who participated in at least one of the two final rounds of an official WTA tournament between 2002 and 2004. It contains detailed information on players (e.g. age, experience, ranking, status during the tournament, number of previous head-to-head matches won and lost against the opponent before the match, number of titles won before the tournament, number of games played in the tournament before the match) and tournaments (e.g. type of tournament, size, 
prize and ranking-points structure, soil of the court, outdoor or indoor tournament, month, year). It includes 1,004 observations for individuals playing 502 matches.

Our methodology is consistent with that of Sunde (2003). As an indicator of heterogeneity in the strength of contestants we use the difference in their WTA ranks. As a sensitivity test, we also rely on the indicator built by Klaassen and Magnus (2003) in order to control for the pyramid structure of players' quality. The prize spread is measured by the difference in prizes between winning and losing a match. In semi-finals, we also add the option value of winning the tournament. Moreover, we weigh this option value by the ability of the future potential contestants whom a player could meet in the final. The performance of a player is measured by the individual number of games won at the end of a match. The existence of a potential selection bias is addressed with Heckman's (1979) two-step estimation procedure.

As far as we know, this paper is the first with Frick and Prinz (2002) to test tournament models for women in professional individualistic sports. Empirical findings support the existence of a positive and significant relationship between prize spread and women's performance, as suggested by tournament models. ${ }^{18}$ These findings are robust to the inclusion of many control variables and to the addition of players' fixed effects. Similar results have been obtained by Sunde (2003) for men. Hence, it appears that both sexes react positively to prize incentives in professional single sex tournaments.

Further results for women indicate that uneven contests lead favourites to win more games and underdogs to be less performing. They also show that the difference in the number of games won by the favourite and the underdog increases with the players' ranking differential. These findings support the capability effect of heterogeneity on players' performance. In other words, they show that the final outcome of a match is more linked to players' abilities (and intrinsic talent) than to players' incentives to adjust their effort according to their success chances. Sunde (2003) found the opposite result for men. He suggests that the incentive effect of heterogeneity is greater than the capability effect. A potential explanation for this dissimilarity is that differences in rankings between players more accurately reflect heterogeneity in abilities between women than between men. ${ }^{19}$

\footnotetext{
${ }^{18}$ However, results indicate that the performance of underdogs (i.e. players with a disadvantage ex ante) is not sensitive to the magnitude of the prize spread.

${ }^{19}$ Other explanations may include the fact that Sunde (2003): i) only focuses on prestigious tournaments where the distribution of players' ability and talent in the two final rounds is generally more compressed and ii) defines
} 


\section{References}

Abrevaya, J. (2002). Ladder tournaments and underdogs. Lessons from professional bowling. Journal of Economic Behaviour and Organization, 47, 87-101.

Becker, B. E., \& Huselid, M. A. (1992). The incentive effects of tournament compensation systems. Administrative Science Quarterly, 37, 336-350.

Bognanno, M.L. (1990), An Empirical Test of Tournament Theory, Ph.D. Thesis, Department of Economics, Cornell University.

Bolton, G. E., \& Katok, E. (1995). An experimental test for gender differences in beneficient behaviour. Economics Letters, 18, 287-292

Brown-Kruse, J., \& Hummels, D. (1993). Gender effects in laboratory public goods contribution: do individuals put their money where their mouth is?. Journal of Economic Behaviour and Organization, 22, 255-267.

Eckel, C., \& Grossman, P. (1998). Are women less selfish than men? Evidence from dictator experiments. Economic Journal, 108, 726-735.

Ehrenberg, R.G., \& Bognanno, M.L. (1990a). Do tournaments have incentive effects?. Journal of Political Economy, 98, 1307-1324.

Ehrenberg, R.G., \& Bognanno, M.L. (1990b). The incentive effects of tournaments revisited: evidence from the European PGA Tour. Industrial and Labor Relations Review, 43, 7488.

Fernie, S., \& Metcalf, D. (1999). It's not what you pay it's the way that you pay it- and that's what gets the results: jockey's pay and performance. Labour: Review of Labour Economics and Industrial Relations, 13, 385-411.

Frick, B., \& Prinz, J. (2002). Pay and performance in professional road running: the case of city marathons. Department of Economics, University of Witten/Herdecke, mimeo.

Gneezy, U., Niederle, M., \& Rustichini, A. (2003). Performance in competitive environments: gender differences. Quarterly Journal of Economics, 118, 1049-1074.

Gneezy, U., \& Rustichini, A. (2004). Gender and competition at a young age. American Economic Review, 94, 377-381.

Greenwald, A., \& Banaji, M. (1995). Implicit social cognition: attitudes, self-esteem, and stereotypes. Psychological Review, 102, 4-27.

the favourite as the player with the best rank vis-à-vis the opponent and does not take into account previous meetings between two players. 
Heckman, J. (1979). Sample selection bias as a specification error. Econometrica, 47, 153162.

Klaassen, F., \& Magnus, J. (2001). Are points in tennis independent and identically distributed? Evidence from a dynamic binary panel data model. Journal of the American Statistical Association, 96, 500-509

Klaassen, F., \& Magnus, J. (2003). Forecasting the winner of a tennis match. European Journal of Operational Research, 148, 257-267.

Knight, J. (2002). Sexual stereotypes. Nature, 415, 254-256.

Lazear, E., \& Rosen, S. (1981). Rank-order tournaments as optimum labour contracts. Journal of Political Economy, 89, 841-864.

Lynch, J. G., \& Zax, J. S. (1998). Prizes, selection, and performance in Arabian horse racing. Working Paper N98-26, Departments of Economics, University of Colorado.

Lynch, J. G., \& Zax, J. S. (2000). The rewards to running: prize structure and performance in professional road racing. Journal of Sports Economics, 1, 323-340.

Maloney, M.T., \& McCormick, R.E. (2000). The response of workers to wages in tournaments: evidence from foot races. Journal of Sports Economics, 1, 99-123.

Prendergast, C. (1999). The provision of incentives in firms. Journal of Economic Literature, $37,7-63$.

Orzag, J. M. (1994). A new look at incentive effects in tournaments. Economic Letters, 46, 77-88.

Rosen, S. (1986). Prizes and incentives in elimination tournaments. American Economic Review, 76, 701-715.

Steele, C. (1997). A threat in the air: how stereotypes shape intellectual identity and performance. Journal of Personality and Social Psychology, 69, 797-811.

Sunde, U. (2003). Potential, prizes and performance: testing tournament theory with professional tennis data. IZA Discussion Paper N 947, Bonn, Germany.

Szymanski, S. (2003). The economic design of sporting contests. Journal of Economic Literature, 41, 1137-1187.

Terkun, K., \& Maloney, M. T. (2000). Road warrior booty: prize structures in motorcycle racing. Unpublished manuscript, Department of Economics, Clemson University.

Von Allmen, P. (2001). Is the reward system in NASCAR efficient?. Journal of Sports Economics, 2, 62-79. 
White, H. (1980). A heteroscedasticity-consistent covariance matrix estimator and a direct test for heteroscedasticity, Econometrica, 48, 817-830. 


\section{Table 1}

Means and standard deviations of selected variables

Number of individual games won

Favourite $^{1}$

Underdog

Heterogeneity (own's - opponent's rank in absolute value)

Favourite

Underdog

Prize money $(1,000 \$)$

Difference of prizes between winning and losing a match + option value Semi-final

Difference of prizes between winning and losing a match + option value

weighted by the relative strength of contestants in the other semi-final Semi-final

Difference of prizes between winning and losing a match + option value weighted by the strength of the better contestant in the other semi-final Semi-final

Difference of prizes between winning and losing the final

Highest prize to win in the tournament

WTA ranking-points

Difference of points between winning and losing a match + option value Semi-final

Difference of points between winning and losing a match + option value weighted by the relative strength of contestants in the other semi-final Semi-final

Difference of points between winning and losing a match + option value weighted by the strength of the better contestant in the other semi-final Semi-final

Difference of points between winning and losing the final

Soil of the court (reference: hard, grass, carpet)

Clay

Outdoor (reference: indoor)

Size: number of players per tournament

Type of tournament (reference: Grand Slams and final of WTA championships)

Tier $\mathrm{V}$

Tier IV

Tier III

Tier II

Tier I

Number of previous head-to-head matches

Number of titles won before the tournament

Age

Experience: number of years on the WTA tour

Number of previous games played in the tournament

Status of the player (reference: seeded)

Unseeded

Qualified and wild card

\begin{tabular}{cc} 
Mean & Std. Dev. \\
\hline 11.15 & 4.22 \\
11.93 & 3.60 \\
10.36 & 4.63 \\
30.87 & 47.90 \\
-22.58 & 52.28 \\
22.58 & 52.28
\end{tabular}

$98.96 \quad 169.39$

$111.61 \quad 186.64$

$\begin{array}{ll}76.93 & 129.93\end{array}$

$78.45 \quad 132.36$

$\begin{array}{ll}73.16 & 124.69\end{array}$

$\begin{array}{ll}72.78 & 124.55\end{array}$

$73.92 \quad 125.13$

$151.33 \quad 248.55$

$94.82 \quad 73.46$

$112.15 \quad 79.29$

$\begin{array}{ll}76.62 & 57.15\end{array}$

$84.75 \quad 61.46$

$72.84 \quad 54.95$

$79.05 \quad 59.06$

$60.54 \quad 43.27$

0.31

0.78

$41.75 \quad 27.37$

\begin{tabular}{lc}
\hline Number of matches & 502 \\
Number of observations & 1,004 \\
\hline ''Favourites' are in general players with the largest share of head-to-head wins. However, if players never met \\
each other or if they won the same number of head-to-head matches, the better ranked player is the favourite.
\end{tabular}


Table $2 A$

Effects of prizes and heterogeneity on player's performance

\begin{tabular}{|c|c|c|c|c|c|c|}
\hline \multicolumn{3}{|c|}{ Dependent variable: Games won by players } & \multirow{2}{*}{\multicolumn{2}{|c|}{$\begin{array}{r}\text { OLS } \\
\text { Model B }\end{array}$}} & \multirow{2}{*}{\multicolumn{2}{|c|}{ Model C }} \\
\hline & Moc & $1 \mathrm{~A}^{1}$ & & & & \\
\hline Prize differential $(1,000 \$)$ & $\begin{array}{l}0.008 * \\
(0.003)\end{array}$ & $\begin{array}{c}0.009 * * \\
(0.003)\end{array}$ & $\begin{array}{c}0.015^{* *} \\
(0.005)\end{array}$ & $\begin{array}{l}0.012 * \\
(0.005)\end{array}$ & $\begin{array}{c}0.014 * * \\
(0.006)\end{array}$ & $\begin{array}{c}0.010^{\circ} \\
(0.006)\end{array}$ \\
\hline Heterogeneity & $\begin{array}{c}-0.009 * * \\
(0.003)\end{array}$ & & $\begin{array}{c}-0.009 * * \\
(0.003)\end{array}$ & & $\begin{array}{c}-0.009 * * \\
(0.003)\end{array}$ & \\
\hline Heterogeneity in square & $\begin{array}{c}-2.29 \mathrm{E}-06 \\
(1.2 \mathrm{E}-05)\end{array}$ & & $\begin{array}{c}-1.97 \mathrm{E}-06 \\
(1.2 \mathrm{E}-05)\end{array}$ & & $\begin{array}{l}-2.09 \mathrm{E}-06 \\
(1.2 \mathrm{E}-05)\end{array}$ & \\
\hline Favourite $(-50<=\text { Het }<-10)^{2}$ & & $\begin{array}{l}-0.320 \\
(0.416)\end{array}$ & & $\begin{array}{l}-0.352 \\
(0.416)\end{array}$ & & $\begin{array}{l}-0.337 \\
(0.416)\end{array}$ \\
\hline Weak favourite $(-10<=$ Het $<0)$ & & $\begin{array}{c}0.364 \\
(0.458)\end{array}$ & & $\begin{array}{c}0.268 \\
(0.462)\end{array}$ & & $\begin{array}{c}0.287 \\
(0.464)\end{array}$ \\
\hline Weak underdog $(0<$ Het $<=10)$ & & $\begin{array}{c}-1.319^{* *} \\
(0.496)\end{array}$ & & $\begin{array}{c}-1.383^{* *} \\
(0.495)\end{array}$ & & $\begin{array}{c}-1.369 * * \\
(0.496)\end{array}$ \\
\hline Underdog $(10<\mathrm{Het}<=50)$ & & $\begin{array}{c}-2.964 * * \\
(0.540)\end{array}$ & & $\begin{array}{c}-2.926^{* *} \\
(0.538)\end{array}$ & & $\begin{array}{c}-2.909 * * \\
(0.538)\end{array}$ \\
\hline Very weak underdog $($ Het>50) & & $\begin{array}{c}-3.255^{* *} \\
(0.718)\end{array}$ & & $\begin{array}{c}-3.171 * * \\
(0.715)\end{array}$ & & $\begin{array}{c}-3.174 * * \\
(0.714)\end{array}$ \\
\hline Tournament characteristics $^{3}$ & Yes & Yes & Yes & Yes & Yes & Yes \\
\hline Player characteristics ${ }^{4}$ & Yes & Yes & Yes & Yes & Yes & Yes \\
\hline Constant & $\begin{array}{c}9.25 * * \\
(2.36)\end{array}$ & $\begin{array}{c}9.85 * * \\
(2.39)\end{array}$ & $\begin{array}{l}7.68 * * \\
(2.52)\end{array}$ & $\begin{array}{c}9.73 * * \\
(2.50)\end{array}$ & $\begin{array}{c}8.03 * * \\
(2.67)\end{array}$ & $\begin{array}{c}10.48 * * \\
(2.66)\end{array}$ \\
\hline $\mathrm{N}$ & 1,004 & 1,004 & 1,004 & 1,004 & 1,004 & 1,004 \\
\hline Adj. $R^{2}$ & 0.06 & 0.11 & 0.06 & 0.10 & 0.06 & 0.10 \\
\hline F-stat & $3.02 * *$ & $4.59 * *$ & $3.04 * *$ & $4.56^{* *}$ & $3.01 * *$ & $4.46^{* *}$ \\
\hline \multicolumn{7}{|c|}{$\begin{array}{l}\text { Notes: } * * / * / 0 \text { indicate significance at the } 1,5 \text { and } 10 \% \text { level, respectively. White (1980) heteroscedasticity } \\
\text { consistent standard errors are reported between brackets. }{ }^{1} \text { In Model A, the prize differential is measured by the } \\
\text { difference of prizes between winning and losing a match plus the option value of further prizes when a } \\
\text { contestant plays a semi-final match (i.e. the prize differential between the winner and the loser of the final). In } \\
\text { Model B, the option value is weighted by the relative strength of the contestants in the other semi-final match. In } \\
\text { Model C, we weigh the option value by the strength of the best player in the other semi-final match. }{ }^{2} \text { The } \\
\text { category of reference is super favourite players (i.e. with Het }<-50) .{ }^{3} \text { Tournament characteristics include: } \\
\text { category of tournament ( } 5 \text { dummies), overall prize money, soil of the court ( } 1 \text { dummy), indoor or outdoor ( } 1 \\
\text { dummy), size (number of players in the tournament), year ( } 2 \text { dummies), month ( } 9 \text { dummies). }{ }^{4} \text { Player } \\
\text { characteristics include: age, number of titles won before the match, number of previous games played in the } \\
\text { tournament before the match, share of head-to-head won, player's status ( } 1 \text { dummy), final ( } 1 \text { dummy). }\end{array}$} \\
\hline
\end{tabular}


Table $2 B$

Effects of prizes and heterogeneity on player's performance (Fixed effects $v s$. Random effects)

\begin{tabular}{|c|c|c|c|c|c|c|c|c|c|c|c|c|}
\hline \multicolumn{7}{|c|}{ Dependent variable: Games won by players } & \multicolumn{6}{|c|}{ Random Effects: GLS } \\
\hline & \multicolumn{2}{|c|}{ Model $\mathrm{A}^{1}$} & \multicolumn{2}{|c|}{ Model B } & \multicolumn{2}{|c|}{ Model C } & \multicolumn{2}{|c|}{ Model A } & \multicolumn{2}{|c|}{ Model B } & \multicolumn{2}{|c|}{ Model C } \\
\hline Prize differential $(1,000 \$)$ & $\begin{array}{l}0.006^{*} \\
(0.003)\end{array}$ & $\begin{array}{c}0.007^{*} \\
(0.003)\end{array}$ & $\begin{array}{c}0.009 \\
(0.006)\end{array}$ & $\begin{array}{c}0.008 \\
(0.006)\end{array}$ & $\begin{array}{c}0.007 \\
(0.007)\end{array}$ & $\begin{array}{c}0.005 \\
(0.007)\end{array}$ & $\begin{array}{l}0.008^{*} \\
(0.004)\end{array}$ & $\begin{array}{c}0.009 * * \\
(0.003)\end{array}$ & $\begin{array}{l}0.015^{* *} \\
(0.005)\end{array}$ & $\begin{array}{l}0.012 * \\
(0.005)\end{array}$ & $\begin{array}{l}0.006^{*} \\
(0.003)\end{array}$ & $\begin{array}{c}0.010^{\circ} \\
(0.006)\end{array}$ \\
\hline Heterogeneity & $\begin{array}{c}-0.010 * * \\
(0.004)\end{array}$ & & $\begin{array}{c}-0.010^{* *} \\
(0.003)\end{array}$ & & $\begin{array}{c}-0.010^{* *} \\
(0.003)\end{array}$ & & $\begin{array}{c}-0.009 * * \\
(0.003)\end{array}$ & & $\begin{array}{c}-0.009 * * \\
(0.003)\end{array}$ & & $\begin{array}{c}-0.009 * * \\
(0.003)\end{array}$ & \\
\hline Heterogeneity in square & $\begin{array}{r}-5.41 \mathrm{E}-06 \\
(1.4 \mathrm{E}-05)\end{array}$ & & $\begin{array}{l}-5.42 \mathrm{E}-06 \\
(1.4 \mathrm{E}-05)\end{array}$ & & $\begin{array}{l}-5.48 \mathrm{E}-06 \\
(1.4 \mathrm{E}-05)\end{array}$ & & $\begin{array}{l}-2.29 \mathrm{E}-06 \\
(1.2 \mathrm{E}-05)\end{array}$ & & $\begin{array}{l}-1.97 \mathrm{E}-06 \\
(1.1 \mathrm{E}-05)\end{array}$ & & $\begin{array}{l}-2.09 \mathrm{E}-06 \\
(1.1 \mathrm{E}-05)\end{array}$ & \\
\hline Favourite $(-50<=\text { Het }<-10)^{2}$ & & $\begin{array}{c}0.040 \\
(0.462)\end{array}$ & & $\begin{array}{l}-0.001 \\
(0.464)\end{array}$ & & $\begin{array}{c}0.011 \\
(0.464)\end{array}$ & & $\begin{array}{l}-0.111 \\
(0.426)\end{array}$ & & $\begin{array}{l}-0.161 \\
(0.429)\end{array}$ & & $\begin{array}{l}-0.153 \\
(0.428)\end{array}$ \\
\hline Weak favourite $(-10<=$ Het $<0)$ & & $\begin{array}{c}0.619 \\
(0.510)\end{array}$ & & $\begin{array}{c}0.549 \\
(0.518)\end{array}$ & & $\begin{array}{c}0.566 \\
(0.521)\end{array}$ & & $\begin{array}{c}0.590 \\
(0.467)\end{array}$ & & $\begin{array}{c}0.476 \\
(0.474)\end{array}$ & & $\begin{array}{c}0.481 \\
(0.475)\end{array}$ \\
\hline Weak underdog $(0<$ Het $<=10)$ & & $\begin{array}{c}-1.319 * \\
(0.539)\end{array}$ & & $\begin{array}{c}-1.387^{*} \\
(0.540)\end{array}$ & & $\begin{array}{c}-1.378^{*} \\
(0.541)\end{array}$ & & $\begin{array}{c}-1.050^{*} \\
(0.509)\end{array}$ & & $\begin{array}{c}-1.142^{*} \\
(0.510)\end{array}$ & & $\begin{array}{c}-1.135^{*} \\
(0.511)\end{array}$ \\
\hline Underdog $(10<$ Het $<=50)$ & & $\begin{array}{c}-2.726^{* *} \\
(0.597)\end{array}$ & & $\begin{array}{c}-2.724 * * \\
(0.597)\end{array}$ & & $\begin{array}{c}-2.702 * * \\
(0.597)\end{array}$ & & $\begin{array}{c}-2.729 * * \\
(0.547)\end{array}$ & & $\begin{array}{c}-2.711^{* *} \\
(0.546)\end{array}$ & & $\begin{array}{c}-2.700 * * \\
(0.546)\end{array}$ \\
\hline Very weak underdog $($ Het>50) & & $\begin{array}{c}-3.704^{* *} \\
(0.795)\end{array}$ & & $\begin{array}{c}-3.661 * * \\
(0.793)\end{array}$ & & $\begin{array}{c}-3.653 * * \\
(0.793)\end{array}$ & & $\begin{array}{c}-3.034 * * \\
(0.708)\end{array}$ & & $\begin{array}{c}-2.968 * * \\
(0.706)\end{array}$ & & $\begin{array}{c}-2.973 * * \\
(0.705)\end{array}$ \\
\hline Tournament characteristics ${ }^{3}$ & Yes & Yes & Yes & Yes & Yes & Yes & Yes & Yes & Yes & Yes & Yes & Yes \\
\hline Player characteristics ${ }^{4}$ & Yes & Yes & Yes & Yes & Yes & Yes & Yes & Yes & Yes & Yes & Yes & Yes \\
\hline Constant & $\begin{array}{l}-1.04 \\
(5.30)\end{array}$ & $\begin{array}{l}-0.28 \\
(5.23)\end{array}$ & $\begin{array}{l}-1.48 \\
(5.64)\end{array}$ & $\begin{array}{l}-0.53 \\
(5.52)\end{array}$ & $\begin{array}{l}-0.81 \\
(5.79)\end{array}$ & $\begin{array}{c}0.92 \\
(5.62)\end{array}$ & $\begin{array}{l}9.25 * * \\
(2.36)\end{array}$ & $\begin{array}{l}9.65 * * \\
(2.40)\end{array}$ & $\begin{array}{l}7.68 * * \\
(2.52)\end{array}$ & $\begin{array}{l}9.50 * * \\
(2.50)\end{array}$ & $\begin{array}{l}8.03 * * \\
(2.67)\end{array}$ & $\begin{array}{c}10.26^{* *} \\
(2.64)\end{array}$ \\
\hline $\mathrm{N}$ & 1,004 & 1,004 & 1,004 & 1,004 & 1,004 & 1,004 & 1,004 & 1,004 & 1,004 & 1,004 & 1,004 & 1,004 \\
\hline Adj. $\mathrm{R}^{2}$ & 0.10 & 0.15 & 0.10 & 0.15 & 0.10 & 0.15 & 0.04 & 0.05 & 0.05 & 0.05 & 0.05 & 0.05 \\
\hline F-stat & $3.07 * *$ & $4.51 * *$ & $3.00^{* *}$ & $4.45^{* *}$ & $2.95^{* *}$ & $4.33^{* *}$ & & & & & & \\
\hline F-test for fixed effects: $p$-value & $0.00 * *$ & $0.00 * *$ & $0.00 * *$ & $0.00 * *$ & $0.00 * *$ & $0.00 * *$ & & & & & & \\
\hline Wald Chi2 & & & & & & & $100.9^{* *}$ & $156.1^{* *}$ & $102.4^{* *}$ & $158.1^{* *}$ & $99.02 * *$ & $152.4 * *$ \\
\hline $\begin{array}{l}\text { Breusch and Pagan LM test for } \\
\text { random effects: } p \text {-value }\end{array}$ & & & & & & & 0.98 & 0.76 & 0.93 & 0.78 & 0.90 & 0.79 \\
\hline
\end{tabular}


Table $3 A$

Effects of prizes and heterogeneity on player's performance: Favourites vs. Underdogs (OLS)

\begin{tabular}{|c|c|c|c|c|c|c|}
\hline \multirow[t]{2}{*}{ Dependent variable } & \multicolumn{3}{|c|}{ Games won by 'favourites' ${ }^{1}$} & \multicolumn{3}{|c|}{ Games won by 'underdogs'² } \\
\hline & Model $\mathrm{A}^{3}$ & Model B & Model C & Model A & Model B & Model C \\
\hline \multirow[t]{2}{*}{ Prize differential $(1,000 \$)$} & $0.012 * *$ & $0.015^{*}$ & $0.018^{*}$ & 0.005 & 0.012 & 0.007 \\
\hline & $(0.004)$ & $(0.008)$ & $(0.009)$ & $(0.005)$ & $(0.009)$ & $(0.009)$ \\
\hline \multirow[t]{2}{*}{ Heterogeneity (difference in players' ranks) } & $-0.010 *$ & $-0.010 *$ & $-0.010^{*}$ & $-0.009^{\circ}$ & $-0.009^{\circ}$ & $-0.009^{\circ}$ \\
\hline & $(0.005)$ & $(0.005)$ & $(0.005)$ & $(0.005)$ & $(0.005)$ & $(0.005)$ \\
\hline Tournament characteristics ${ }^{4}$ & Yes & Yes & Yes & Yes & Yes & Yes \\
\hline Player characteristics ${ }^{5}$ & Yes & Yes & Yes & Yes & Yes & Yes \\
\hline Individual fixed effects & No & No & No & No & No & No \\
\hline \multirow[t]{2}{*}{ Constant } & $6.49 *$ & $6.80^{\circ}$ & $6.06^{\circ}$ & $11.90 * *$ & $9.98 * *$ & $11.38^{* *}$ \\
\hline & $(2.90)$ & $(3.54)$ & $(3.71)$ & $(3.63)$ & $(3.92)$ & $(4.14)$ \\
\hline $\mathrm{N}$ & 502 & 502 & 502 & 502 & 502 & 502 \\
\hline Adj. $\mathrm{R}^{2}$ & 0.03 & 0.02 & 0.02 & 0.08 & 0.08 & 0.08 \\
\hline F-stat & $1.45^{*}$ & $1.35^{\circ}$ & 1.32 & $3.07 * *$ & $3.11 * *$ & $3.07 * *$ \\
\hline
\end{tabular}

Notes: $* * / * / \circ$ indicate significance at the 1, 5 and $10 \%$ level, respectively. White (1980) heteroscedasticity consistent standard errors are reported between brackets. 1 'Favourites' are in general players with the largest share of head-to-head wins. However, if players never met each other before or if they won the same number of head-tohead matches, the better ranked player is the favourite. ${ }^{2}$ 'Underdogs' are in general players with the lowest share of head-to-head wins. However, if players never met each other before or if they won the same number of head-to-head matches, the worse ranked player is the underdog. ${ }^{3}$ In Model A, the prize differential is measured by the difference of prizes between winning and losing a match plus the option value of further prizes when a contestant plays a semi-final match (i.e. the prize differential between the winner and the loser of the final). In Model B, the option value is weighted by the relative strength of the contestants in the other semi-final match. In Model C, we weigh the option value by the strength of the best player in the other semi-final match. ${ }^{4}$ Tournament characteristics include: category of tournament (5 dummies), overall prize money, soil of the court ( 1 dummy), indoor or outdoor ( 1 dummy), size (number of players in the tournament), year ( 2 dummies), month ( 9 dummies). ${ }^{5}$ Player characteristics include: age, number of titles won before the match, number of previous games played in the tournament before the match, share of head-to-head won, player's status (1 dummy), final (1 dummy). 
Table $3 B$

Effects of prizes and heterogeneity on player's performance: Favourites $v s$. Underdogs (OLS with fixed effects)

\begin{tabular}{|c|c|c|c|c|c|c|}
\hline \multirow[t]{2}{*}{ Dependent variable } & \multicolumn{3}{|c|}{ Games won by 'favourites' ${ }^{1}$} & \multicolumn{3}{|c|}{ Games won by 'underdogs' ${ }^{2}$} \\
\hline & Model $\mathrm{A}^{3}$ & Model B & Model C & Model A & Model B & Model C \\
\hline \multirow[t]{2}{*}{ Prize differential $(1,000 \$)$} & $0.011^{*}$ & $0.013^{\circ}$ & 0.013 & 0.003 & 0.002 & 0.000 \\
\hline & $(0.005)$ & $(0.008)$ & $(0.010)$ & $(0.006)$ & $(0.011)$ & $(0.011)$ \\
\hline \multirow[t]{2}{*}{ Heterogeneity (difference in players' ranks) } & $-0.011 *$ & $-0.011 *$ & $-0.011 *$ & $-0.013^{\circ}$ & $-0.012^{\circ}$ & $-0.012^{\circ}$ \\
\hline & $(0.005)$ & $(0.006)$ & $(0.006)$ & $(0.008)$ & $(0.007)$ & $(0.007)$ \\
\hline Tournament characteristics ${ }^{4}$ & Yes & Yes & Yes & Yes & Yes & Yes \\
\hline Player characteristics ${ }^{5}$ & Yes & Yes & Yes & Yes & Yes & Yes \\
\hline Individual fixed effects & Yes & Yes & Yes & Yes & Yes & Yes \\
\hline \multirow[t]{2}{*}{ Constant } & -7.05 & -6.29 & -5.99 & -2.05 & -1.62 & -0.63 \\
\hline & $(8.31)$ & $(8.46)$ & $(8.47)$ & $(8.27)$ & $(8.86)$ & $(9.22)$ \\
\hline $\mathrm{N}$ & 502 & 502 & 502 & 502 & 502 & 502 \\
\hline Adj. $\mathrm{R}^{2}$ & 0.09 & 0.08 & 0.08 & 0.12 & 0.11 & 0.12 \\
\hline F-stat & $1.49 *$ & $1.30^{\circ \circ}$ & $1.28^{\circ \circ}$ & $1.83 * *$ & $1.78^{* *}$ & $1.77 * *$ \\
\hline F-test for significance of individual fixed effects: $p$-value & $0.00 * *$ & $0.00 * *$ & $0.00 * *$ & 0.12 & 0.12 & 0.11 \\
\hline
\end{tabular}

Notes: $* * / * / 0 / 00$ indicate significance at the $1,5,10$ and $15 \%$ level, respectively. White (1980) heteroscedasticity consistent standard errors are reported between brackets. ${ }^{1}$ 'Favourites' are in general players with the largest share of head-to-head wins. However, if players never met each other before or if they won the same number of head-tohead matches, the better ranked player is the favourite. ${ }^{2}$ 'Underdogs' are in general players with the lowest share of head-to-head wins. However, if players never met each other before or if they won the same number of head-to-head matches, the worse ranked player is the underdog. ${ }^{3}$ In Model A, the prize differential is measured by the difference of prizes between winning and losing a match plus the option value of further prizes when a contestant plays a semi-final match (i.e. the prize differential between the winner and the loser of the final). In Model B, the option value is weighted by the relative strength of the contestants in the other semi-final match. In Model C, we weigh the option value by the strength of the best player in the other semi-final match. ${ }^{4}$ Tournament characteristics include: category of tournament (5 dummies), overall prize money, soil of the court ( 1 dummy), indoor or outdoor ( 1 dummy), size (number of players in the tournament), year ( 2 dummies), month (9 dummies). ${ }^{5}$ Player characteristics include: age, number of titles won before the match, number of previous games played in the tournament before the match, share of head-to-head won, player's status (1 dummy), final (1 dummy). 


\section{Table 4}

Effects of prizes and heterogeneity on difference of games won between the favourite and underdog per match ${ }^{1}$

\begin{tabular}{lccc}
\hline & Model A & Model B & Model C \\
\cline { 2 - 4 } Prize differential $(1,000 \$)$ & $0.009^{\circ \circ}$ & 0.007 & 0.010 \\
& $(0.006)$ & $(0.012)$ & $(0.013)$ \\
Heterogeneity (difference in players' ranks) & $0.017^{\circ}$ & $0.018^{\circ}$ & $0.018^{\circ}$ \\
& $(0.010)$ & $(0.011)$ & $(0.011)$ \\
Heterogeneity in square & $-3.17 \mathrm{E}-05$ & $-3.39 \mathrm{E}-05$ & $-3.47 \mathrm{E}-05$ \\
& $(3.04 \mathrm{E}-05)$ & $(3.29 \mathrm{E}-05)$ & $(3.29 \mathrm{E}-05)$ \\
Tournament characteristics $^{3}$ & Yes & Yes & Yes \\
Match characteristics $^{4}$ & Yes & Yes & Yes \\
Constant & $-6.55^{\circ}$ & -4.79 & -6.02 \\
N & $(3.53)$ & $(4.95)$ & $(5.15)$ \\
Adj. $\mathrm{R}^{2}$ & 502 & 502 & 502 \\
F-stat & 0.13 & 0.13 & 0.13 \\
\hline
\end{tabular}

Notes: $* * / 0 / 00$ indicate significance at the 1,10 and $15 \%$ level, respectively. White (1980) heteroscedasticity consistent standard errors are reported between brackets. ${ }^{1}$ 'Favourites' are in general players with the largest share of head-to-head wins. However, if players never met each other before or if they won the same number of head-to-head matches, the better ranked player is the favourite. ${ }^{2}$ Model A, the prize differential is measured by the difference of prizes between winning and losing a match plus the option value of further prizes when a contestant plays a semi-final match (i.e. the prize differential between the winner and the loser of the final). In Model B, the option value is weighted by the relative strength of the contestants in the other semi-final match. In Model $\mathrm{C}$, we weigh the option value by the strength of the best player in the other semi-final match. Tournament characteristics include: category of tournament ( 5 dummies), overall prize money, soil of the court (1 dummy), indoor or outdoor (1 dummy), size (number of players in the tournament), year ( 2 dummies), month (9 dummies). ${ }^{4}$ Match characteristics include the differentials between favourites and underdogs in age, number of previous titles won during the year, number of head-to-head won before the match and number of games played in the tournament before the match. 


\section{Table 5}

Effects of prizes and heterogeneity on player's performance: Better known opponent $v s$. Less known opponent (OLS)

\begin{tabular}{|c|c|c|c|c|c|c|}
\hline \multirow[t]{2}{*}{ Dependent variable: } & \multicolumn{3}{|c|}{ Games won by 'better known opponent' } & \multicolumn{3}{|c|}{ Games won by 'less known opponent' ${ }^{2}$} \\
\hline & Model $\mathrm{A}^{3}$ & Model B & Model C & Model A & Model B & Model C \\
\hline \multirow[t]{2}{*}{ Prize differential $(1,000 \$)$} & $0.012 *$ & $0.019^{*}$ & $0.014^{\circ}$ & 0.006 & $0.015^{*}$ & 0.016 \\
\hline & $(0.005)$ & $(0.008)$ & $(0.008)$ & $(0.007)$ & $(0.007)$ & $(0.008)$ \\
\hline \multirow[t]{2}{*}{ Heterogeneity (difference in players' ranks) } & $-0.015^{\circ}$ & $-0.014^{\circ}$ & $-0.014^{\circ}$ & $-0.007^{*}$ & $-0.007 *$ & $-0.007 *$ \\
\hline & $(0.009)$ & $(0.008)$ & $(0.008)$ & $(0.003)$ & $(0.003)$ & $(0.003)$ \\
\hline Tournament characteristics ${ }^{4}$ & Yes & Yes & Yes & Yes & Yes & Yes \\
\hline Player characteristics ${ }^{5}$ & Yes & Yes & Yes & Yes & Yes & Yes \\
\hline \multirow[t]{2}{*}{ Constant } & $8.08^{*}$ & $6.83^{\circ}$ & $8.56^{*}$ & $12.65^{* *}$ & $10.61 *$ & $9.99 *$ \\
\hline & (3.39) & $(3.93)$ & $(4.15)$ & $(4.00)$ & $(3.32)$ & (3.61) \\
\hline $\mathrm{N}$ & 396 & 396 & 396 & 608 & 608 & 608 \\
\hline Adj. $\mathrm{R}^{2}$ & 0.05 & 0.05 & 0.04 & 0.06 & 0.06 & 0.06 \\
\hline F-stat & $1.72 *$ & $1.66^{*}$ & $1.57 *$ & $2.34 * *$ & $2.40 * *$ & $2.41 * *$ \\
\hline
\end{tabular}

Notes: $* * * / 0$ indicate significance at the 1,5 and $10 \%$ level, respectively. White (1980) heteroscedasticity consistent standard errors are reported between brackets. ${ }^{1}$ 'Better known opponent' refers to matches where individuals already met each other at least three times. ${ }^{2}$ 'Less known opponent' refers to matches where individuals have played each other two times at best. ${ }^{3}$ In Model A, the prize differential is measured by the difference of prizes between winning and losing a match plus the option value of further prizes when a contestant plays a semi-final match (i.e. the prize differential between the winner and the loser of the final). In Model $\mathrm{B}$, the option value is weighted by the relative strength of the contestants in the other semi-final match. In Model C, we weigh the option value by the strength of the best player in the other semi-final match. ${ }^{4}$ Tournament characteristics include: category of tournament ( 5 dummies), overall prize money, soil of the court ( 1 dummy), indoor or outdoor ( 1 dummy), size (number of players in the tournament), year ( 2 dummies), month (9 dummies). ${ }^{5}$ Player characteristics include: age, number of titles won before the match, number of previous games played in the tournament before the match, share of head-to-head won, player's status ( 1 dummy), final ( 1 dummy). 
Table 6

Effects of prizes and heterogeneity on player's performance

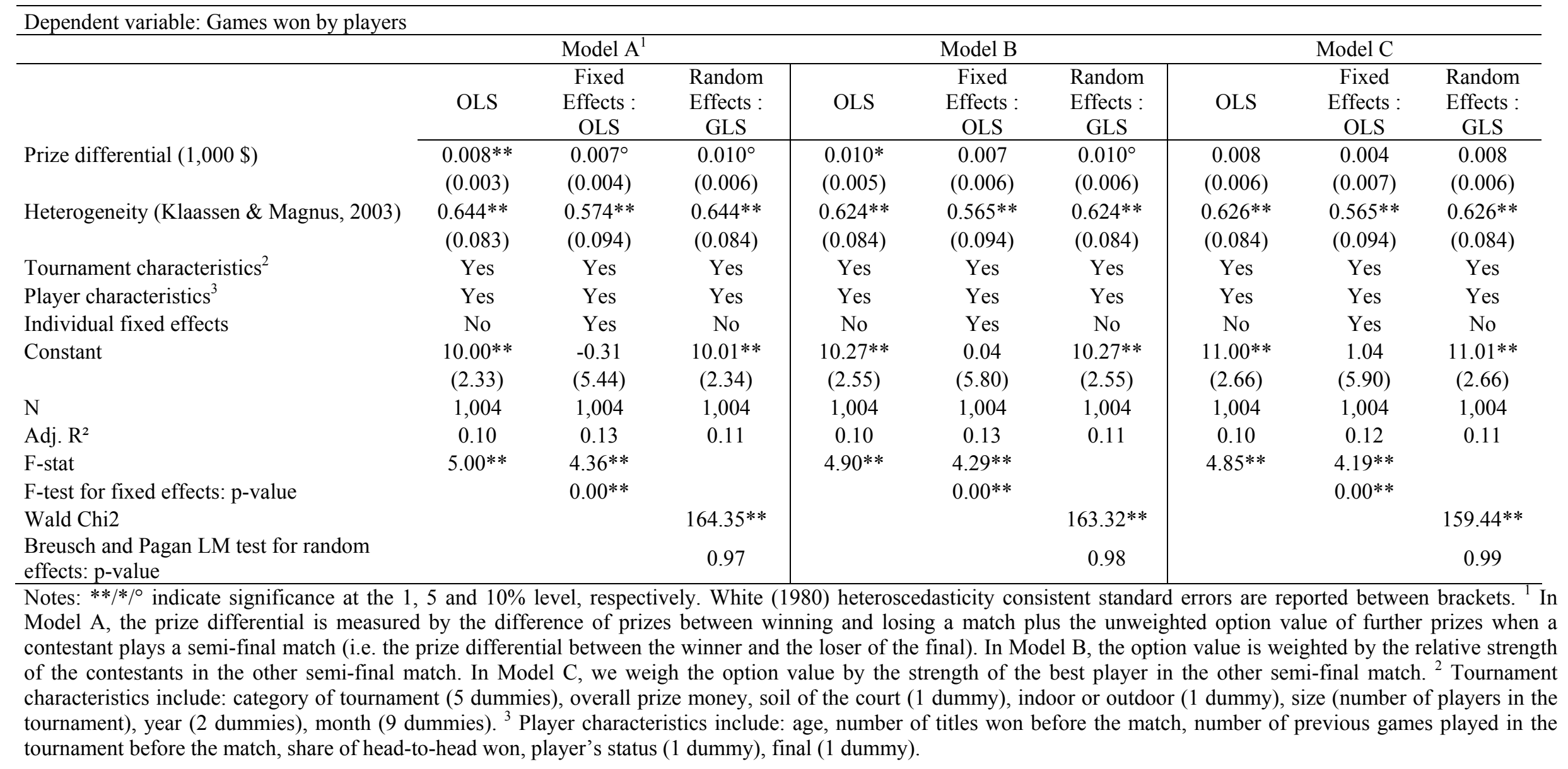


Table 7

Selection model: Heckman (1979) two-step procedure

\begin{tabular}{|c|c|}
\hline \multicolumn{2}{|c|}{ Final regression } \\
\hline Prize differential $(1,000 \$)$ & $\begin{array}{l}-0.020 \\
(0.017)\end{array}$ \\
\hline Heterogeneity (final) & $\begin{array}{c}-0.013 * * \\
(0.004)\end{array}$ \\
\hline Heterogeneity in square & $\begin{array}{l}-2.38 \mathrm{E}-05^{\circ} \\
(1.41 \mathrm{E}-05)\end{array}$ \\
\hline Constant & $\begin{array}{c}5.21 \\
(7.08)\end{array}$ \\
\hline Inverse Mill's ratio & $\begin{array}{l}3.72 * \\
(1.75)\end{array}$ \\
\hline Tournament characteristics ${ }^{1}$ & Yes \\
\hline Player characteristics ${ }^{2}$ & Yes \\
\hline Uncensored observations & 337 \\
\hline Wald Chi2(53) & $295.93 * *$ \\
\hline \multicolumn{2}{|c|}{ Selection equation } \\
\hline Option value $(1,000 \$)$ & $\begin{array}{l}-0.007^{\circ} \\
(0.004)\end{array}$ \\
\hline Heterogeneity (semifinal) & $\begin{array}{l}-0.002 * \\
(0.001)\end{array}$ \\
\hline Constant & $\begin{array}{l}-1.41 \\
(1.24)\end{array}$ \\
\hline Tournament characteristics $^{2}$ & Yes \\
\hline Player characteristics ${ }^{3}$ & Yes \\
\hline $\mathrm{N}$ & 1,004 \\
\hline LR Chi2(27) & $343.48 * *$ \\
\hline Pseudo $\mathrm{R}^{2}$ & 0.27 \\
\hline
\end{tabular}

Notes: $* * / * /{ }^{\circ}$ indicate significance at the 1,5 and $10 \%$ level, respectively. Standard errors are reported between brackets. ${ }^{1}$ Tournament characteristics include: category of tournament (5 dummies), overall prize money, soil of the court (1 dummy), indoor or outdoor (1 dummy), size (number of players in the tournament), year (2 dummies), month (9 dummies). ${ }^{2}$ Player characteristics include: age, number of titles won before the match, number of previous games played in the tournament before the match, share of head-tohead won, player's status (1 dummy), final (1 dummy). 


\section{APPENDIX}

Table A1

Effects of prizes and heterogeneity on player's performance

\begin{tabular}{|c|c|c|c|c|c|c|}
\hline \multicolumn{7}{|c|}{ Dependent variable: Games won by players } \\
\hline \multirow{3}{*}{ Prize differential $(1,000 \$)$} & \multicolumn{2}{|c|}{ Model $\mathrm{A}^{1}$} & \multicolumn{2}{|c|}{ Model B } & \multicolumn{2}{|c|}{ Model C } \\
\hline & $0.008^{*}$ & $0.006^{*}$ & $0.015 * *$ & 0.009 & $0.014 * *$ & 0.007 \\
\hline & $(0.004)$ & $(0.003)$ & $(0.005)$ & $(0.006)$ & $(0.006)$ & $(0.007)$ \\
\hline \multirow[t]{2}{*}{ Heterogeneity } & $-0.009 * *$ & $-0.010 * *$ & $-0.009 * *$ & $-0.010 * *$ & $-0.009 * *$ & $-0.010 * *$ \\
\hline & $(0.003)$ & $(0.003)$ & $(0.003)$ & $(0.003)$ & $(0.003)$ & $(0.003)$ \\
\hline \multirow[t]{2}{*}{ Heterogeneity in square } & $-2.29 \mathrm{E}-06$ & $-5.41 \mathrm{E}-06$ & $-1.97 \mathrm{E}-06$ & $-5.42 \mathrm{E}-06$ & $-2.09 \mathrm{E}-06$ & $-5.48 \mathrm{E}-06$ \\
\hline & $(1.2 \mathrm{E}-05)$ & $(1.4 \mathrm{E}-05)$ & $(1.2 \mathrm{E}-05)$ & $(1.4 \mathrm{E}-05)$ & $(1.2 \mathrm{E}-05)$ & $(1.4 \mathrm{E}-05)$ \\
\hline \multirow{2}{*}{ Final (ref: semi-final) } & 0.563 & 0.255 & 0.366 & 0.089 & 0.278 & 0.026 \\
\hline & $(0.366)$ & $(0.382)$ & $(0.340)$ & $(0.364)$ & $(0.336)$ & $(0.358)$ \\
\hline \multirow[t]{2}{*}{ Clay court (ref: grass, hard, carpet) } & $1.050 *$ & $1.488^{*}$ & $1.090 *$ & $1.416^{*}$ & $1.106^{*}$ & $1.424^{*}$ \\
\hline & $(0.515)$ & $(0.623)$ & $(0.512)$ & $(0.620)$ & $(0.516)$ & $(0.624)$ \\
\hline \multirow{2}{*}{ Outdoor court (ref: indoor) } & 0.726 & $1.348^{*}$ & 0.675 & $1.328 *$ & 0.682 & $1.348 *$ \\
\hline & $(0.480)$ & $(0.538)$ & $(0.483)$ & $(0.541)$ & $(0.483)$ & $(0.541)$ \\
\hline \multirow[t]{2}{*}{ Size of tournament } & -0.0003 & -0.005 & 0.004 & -0.004 & 0.004 & -0.005 \\
\hline & $(0.012)$ & $(0.013)$ & $(0.012)$ & $(0.013)$ & $(0.012)$ & $(0.013)$ \\
\hline \multirow[t]{2}{*}{ Share of head-to-head won } & $1.255^{* *}$ & $0.692^{\circ}$ & $1.172 * *$ & $0.658^{\circ}$ & $1.175^{* *}$ & $0.661^{\circ}$ \\
\hline & $(0.340)$ & $(0.381)$ & $(0.341)$ & $(0.381)$ & $(0.341)$ & $(0.382)$ \\
\hline \multirow[t]{2}{*}{ Number of titles won } & $0.268 * *$ & -0.115 & $0.235^{*}$ & -0.123 & $0.239 *$ & -0.118 \\
\hline & $(0.094)$ & $(0.114)$ & $(0.095)$ & $(0.115)$ & $(0.095)$ & $(0.115)$ \\
\hline \multirow[t]{2}{*}{ Age } & $-0.105^{*}$ & $0.418^{\circ}$ & $-0.097 *$ & $0.431^{\circ}$ & $-0.095^{*}$ & $0.436^{\circ}$ \\
\hline & $(0.037)$ & $(0.207)$ & $(0.037)$ & $(0.209)$ & $(0.037)$ & $(0.209)$ \\
\hline \multirow[t]{2}{*}{ Number of games previously played } & -0.011 & $-0.022 *$ & -0.011 & $-0.022 *$ & -0.011 & $-0.021 *$ \\
\hline & $(0.009)$ & $(0.010)$ & $(0.008)$ & $(0.010)$ & $(0.009)$ & $(0.010)$ \\
\hline \multirow[t]{2}{*}{ Unseeded (ref: seeded) } & -0.360 & 0.105 & -0.245 & 0.137 & -0.266 & 0.113 \\
\hline & $(0.404)$ & $(0.506)$ & $(0.409)$ & $(0.507)$ & $(0.409)$ & $(0.507)$ \\
\hline Year and month dummies ${ }^{2}$ & Yes & Yes & Yes & Yes & Yes & Yes \\
\hline Tournament dummies $^{3}$ & Yes & Yes & Yes & Yes & Yes & Yes \\
\hline Individual fixed effects & No & Yes & No & Yes & No & Yes \\
\hline \multirow[t]{2}{*}{ Constant } & $9.25 * *$ & -1.04 & $7.68 * *$ & -1.48 & $8.03 * *$ & -0.81 \\
\hline & $(2.36)$ & $(5.31)$ & $(2.52)$ & $(5.64)$ & $(2.67)$ & $(5.79)$ \\
\hline $\mathrm{N}$ & 1,004 & 1,004 & 1,004 & 1,004 & 1,004 & 1,004 \\
\hline Adj. $R^{2}$ & 0.06 & 0.10 & 0.06 & 0.10 & 0.06 & 0.10 \\
\hline F-stat & $3.02 * *$ & $3.07 * *$ & $3.04 * *$ & $3.00 * *$ & $3.01 * *$ & $2.95 * *$ \\
\hline F-test for fixed effects: $p$-value & & $0.00 * *$ & & $0.00 * *$ & & $0.00 * *$ \\
\hline $\begin{array}{l}\text { Fraction of variance due to fixed } \\
\text { effects }\end{array}$ & & 0.48 & & 0.48 & & 0.48 \\
\hline
\end{tabular}

Notes: $* * / * / 0$ indicate significance at the 1, 5 and $10 \%$ level, respectively. White (1980) heteroscedasticity consistent standard errors are reported between brackets. ${ }^{1}$ In Model A, the prize differential is measured by the difference of prizes between winning and losing a match plus the option value of further prizes when a contestant plays a semi-final match (i.e. the prize differential between the winner and the loser of the final). In Model B, the option value is weighted by the relative strength of the contestants in the other semi-final match. In Model C, we weigh the option value by the strength of the best player in the other semi-final match. ${ }^{2}$ Year (2 dummies), month (9 dummies). ${ }^{3}$ Type of tournament (5 dummies). 
Table A2

Effects of prizes and heterogeneity on player's performance: Favourites (Fixed effects $v s$. Random effects)

\begin{tabular}{|c|c|c|c|c|c|c|}
\hline \multirow[t]{2}{*}{ Dependent variable: Games won by 'favourites' ${ }^{1}$} & \multicolumn{3}{|c|}{ Fixed Effects: OLS } & \multicolumn{3}{|c|}{ Random Effects: GLS } \\
\hline & Model $\mathrm{A}^{2}$ & Model B & Model C & Model A & Model B & Model C \\
\hline \multirow[t]{2}{*}{ Prize differential $(1,000 \$)$} & $0.011^{*}$ & $0.013^{\circ}$ & 0.013 & $0.012 * *$ & $0.014^{\circ}$ & $0.016^{\circ}$ \\
\hline & $(0.005)$ & $(0.008)$ & $(0.010)$ & $(0.004)$ & $(0.008)$ & $(0.009)$ \\
\hline \multirow[t]{2}{*}{ Heterogeneity (difference in players' ranks) } & $-0.011 *$ & $-0.011 *$ & $-0.011 *$ & $-0.011 *$ & $-0.010^{*}$ & $-0.010^{*}$ \\
\hline & $(0.005)$ & $(0.006)$ & $(0.005)$ & $(0.005)$ & $(0.005)$ & $(0.005)$ \\
\hline Tournament characteristics ${ }^{3}$ & Yes & Yes & Yes & Yes & Yes & Yes \\
\hline Player characteristics ${ }^{4}$ & Yes & Yes & Yes & Yes & Yes & Yes \\
\hline \multirow[t]{2}{*}{ Constant } & -7.05 & -6.29 & -5.99 & $6.25^{*}$ & $6.89^{*}$ & $6.33^{\circ}$ \\
\hline & $(8.31)$ & $(8.46)$ & $(8.47)$ & $(3.20)$ & $(3.79)$ & (3.89) \\
\hline $\mathrm{N}$ & 502 & 502 & 502 & 502 & 502 & 502 \\
\hline Adj. $R^{2}$ & 0.09 & 0.08 & 0.08 & 0.07 & 0.06 & 0.06 \\
\hline F-stat & $1.49 *$ & $1.30^{\circ \circ}$ & $1.28^{\circ 0}$ & & & \\
\hline F-test for significance of individual fixed effects: $p$-value & $0.00 * *$ & $0.00 * *$ & $0.00 * *$ & & & \\
\hline Wald Chi2 & & & & $40.38^{\circ}$ & 32.78 & 32.20 \\
\hline Breusch and Pagan LM test for random effects: p-value & & & & 0.83 & 0.80 & 0.80 \\
\hline
\end{tabular}

Notes: $* * / * / 0$ indicate significance at the $1,5,10$ and $15 \%$ level, respectively. White (1980) heteroscedasticity consistent standard errors are reported between brackets.

'Favourites' are in general players with the largest share of head-to-head wins. However, if players never met each other or if they won the same number of head-to-head matches, the better ranked player is the favourite. ${ }^{2}$ In Model A, the prize differential is measured by the difference of prizes between winning and losing a match plus the option value of further prizes when a contestant plays a semi-final match (i.e. the prize differential between the winner and the loser of the final). In Model B, the option value is weighted by the relative strength of the contestants in the other semi-final match. In Model C, we weigh the option value by the strength of the best player in the other semifinal match. ${ }^{3}$ Tournament characteristics include: category of tournament (5 dummies), overall prize money, soil of the court ( 1 dummy), indoor or outdoor ( 1 dummy), size (number of players in the tournament), year (2 dummies), month ( 9 dummies). ${ }^{4}$ Player characteristics include: age, number of titles won before the match, number of previous games played in the tournament before the match, share of head-to-head won, player's status (1 dummy), final (1 dummy). 
Table A2 (Cont.)

Effects of prizes and heterogeneity on player's performance: Underdogs (Fixed effects $v s$. Random effects)

\begin{tabular}{|c|c|c|c|c|c|c|}
\hline \multirow[t]{2}{*}{ Dependent variable: Games won by 'underdogs ${ }^{1}$} & \multicolumn{3}{|c|}{ Fixed Effects: OLS } & \multicolumn{3}{|c|}{ Random Effects: GLS } \\
\hline & Model $\mathrm{A}^{2}$ & Model B & Model C & Model A & Model B & Model C \\
\hline \multirow[t]{2}{*}{ Prize differential $(1,000 \$)$} & 0.003 & 0.002 & 0.013 & 0.004 & 0.011 & 0.007 \\
\hline & $(0.006)$ & $(0.011)$ & $(0.010)$ & $(0.005)$ & $(0.008)$ & $(0.009)$ \\
\hline \multirow{2}{*}{ Heterogeneity (difference in players' ranks) } & $-0.013^{\circ}$ & $-0.012^{\circ}$ & $-0.011^{*}$ & $-0.009^{\circ}$ & $-0.009^{\circ}$ & $-0.009^{\circ}$ \\
\hline & $(0.008)$ & $(0.007)$ & $(0.006)$ & $(0.005)$ & $(0.005)$ & $(0.005)$ \\
\hline Tournament characteristics ${ }^{3}$ & Yes & Yes & Yes & Yes & Yes & Yes \\
\hline Player characteristics ${ }^{4}$ & Yes & Yes & Yes & Yes & Yes & Yes \\
\hline \multirow[t]{2}{*}{ Constant } & -2.05 & -1.62 & -0.63 & $12.01 * *$ & $10.01 * *$ & $11.44 * *$ \\
\hline & $(8.27)$ & $(8.86)$ & $(9.22)$ & $(3.65)$ & $(3.92)$ & $(4.15)$ \\
\hline $\mathrm{N}$ & 502 & 502 & 502 & 502 & 502 & 502 \\
\hline Adj. $R^{2}$ & 0.12 & 0.11 & 0.12 & 0.15 & 0.16 & 0.15 \\
\hline F-stat & $1.83 * *$ & $1.78 * *$ & $1.77 * *$ & & & \\
\hline F-test for significance of individual fixed effects: $p$-value & $0.12^{\circ 0}$ & $0.12^{\circ \circ}$ & $0.11^{\circ 0}$ & & & \\
\hline Wald Chi2 & & & & $80.86^{* *}$ & $85.74 * *$ & $83.04 * *$ \\
\hline Breusch and Pagan LM test for random effects: p-value & & & & 0.94 & 0.91 & 0.96 \\
\hline
\end{tabular}

Notes: $* * / * / 0$ indicate significance at the 1, 5, 10 and 15\% level, respectively. White (1980) heteroscedasticity consistent standard errors are reported between brackets. 'Underdogs' are in general players with the lowest share of head-to-head wins. However, if players never met each other or if they won the same number of head-to-head matches, the least ranked player is the underdog. ${ }^{2}$ In Model A, the prize differential is measured by the difference of prizes between winning and losing a match plus the option value of further prizes when a contestant plays a semi-final match (i.e. the prize differential between the winner and the loser of the final). In Model B, the option value is weighted by the relative strength of the contestants in the other semi-final match. In Model C, we weigh the option value by the strength of the best player in the other semifinal match. ${ }^{3}$ Tournament characteristics include: category of tournament (5 dummies), overall prize money, soil of the court ( 1 dummy), indoor or outdoor ( 1 dummy), size (number of players in the tournament), year ( 2 dummies), month ( 9 dummies). ${ }^{4}$ Player characteristics include: age, number of titles won before the match, number of previous games played in the tournament before the match, share of head-to-head won, player's status (1 dummy), final (1 dummy). 
Table A3

Effects of prizes and heterogeneity on difference of games won between the favourite and underdog per match ${ }^{1}$

Prize differential $(1,000 \$)$

Heterogeneity (absolute difference in players' ranks)

Heterogeneity in square

Tournament characteristics ${ }^{3}$

Match characteristics ${ }^{4}$

Constant

$\mathrm{N}$

Adj. $\mathrm{R}^{2}$

F-stat

\begin{tabular}{ccc} 
Model $\mathrm{A}^{2}$ & Model B & Model C \\
\hline 0.009 & 0.003 & 0.004 \\
$(0.006)$ & $(0.012)$ & $(0.013)$ \\
$0.021^{*}$ & $0.021^{*}$ & $0.021^{*}$ \\
$(0.011)$ & $(0.011)$ & $(0.011)$ \\
$-4.75 \mathrm{E}-05^{\circ}$ & $-4.83 \mathrm{E}-05^{\circ}$ & $-4.85 \mathrm{E}-05^{\circ}$ \\
$(3.01 \mathrm{E}-05)$ & $(3.01 \mathrm{E}-05)$ & $(3.01 \mathrm{E}-05)$ \\
Yes & Yes & Yes \\
Yes & Yes & Yes \\
-5.68 & -2.54 & -2.74 \\
$(3.77)$ & $(4.97)$ & $(5.16)$ \\
502 & 502 & 502 \\
0.11 & 0.11 & 0.11 \\
$3.24 * *$ & $3.15^{* *}$ & $2.15^{* *}$
\end{tabular}

Notes: $* * / * / 0$ indicate significance at the 1,5 and 10\% level, respectively. White (1980) heteroscedasticity consistent standard errors are reported between brackets. 'Favourite' refers to the better ranked player. ${ }^{2}$ In Model A, the prize differential is measured by the difference of prizes between winning and losing a match plus the option value of further prizes when a contestant plays a semi-final match (i.e. the prize differential between the winner and the loser of the final). In Model B, the option value is weighted by the relative strength of the contestants in the other semi-final match. In Model $\mathrm{C}$, we weigh the option value by the strength of the best player in the other semi-final match. ${ }^{3}$ Tournament characteristics include: category of tournament (5 dummies), overall prize money, soil of the court (1 dummy), indoor or outdoor (1 dummy), size (number of players in the tournament), year ( 2 dummies), month (9 dummies). ${ }^{4}$ Match characteristics include the differentials between favourites and underdogs in age, number of previous titles won during the year, number of head-to-head won before the match and number of games played in the tournament before the match. 
Table A4

Effects of prizes and heterogeneity on player's performance: Better known opponent (Fixed effects vs. Random effects)

\begin{tabular}{|c|c|c|c|c|c|c|}
\hline \multirow[t]{2}{*}{ Dependent variable: Games won by 'better known opponent ${ }^{\text {' }}$} & \multicolumn{3}{|c|}{ Fixed Effects: OLS } & \multicolumn{3}{|c|}{ Random Effects: GLS } \\
\hline & Model $\mathrm{A}^{2}$ & Model B & Model C & Model A & Model B & Model C \\
\hline Prize differential $(1,000 \$)$ & $0.012 *$ & 0.013 & 0.008 & $0.011 *$ & $0.018 *$ & 0.012 \\
\hline & $(0.005)$ & $(0.009)$ & $(0.010)$ & $(0.004)$ & $(0.008)$ & $(0.009)$ \\
\hline Heterogeneity (difference in players' ranks) & $-0.052 *$ & $-0.048 *$ & $-0.048 *$ & $-0.016^{\circ}$ & $-0.014^{\circ}$ & $-0.015^{\circ}$ \\
\hline & $(0.022)$ & $(0.022)$ & $(0.022)$ & $(0.009)$ & $(0.008)$ & $(0.009)$ \\
\hline Tournament characteristics ${ }^{3}$ & Yes & Yes & Yes & Yes & Yes & Yes \\
\hline Player characteristics ${ }^{4}$ & Yes & Yes & Yes & Yes & Yes & Yes \\
\hline Constant & -18.84 & -20.45 & -20.26 & $8.34 *$ & $7.47 *$ & $9.44^{*}$ \\
\hline & (14.37) & (14.88) & $(15.57)$ & $(3.72)$ & $(4.14)$ & $(4.35)$ \\
\hline $\mathrm{N}$ & 396 & 396 & 396 & 396 & 396 & 396 \\
\hline Adj. $R^{2}$ & 0.12 & 0.11 & 0.10 & 0.10 & 0.14 & 0.13 \\
\hline F-stat & $1.69 *$ & $1.54^{*}$ & $1.46^{\circ}$ & & & \\
\hline F-test for significance of individual fixed effects: $p$-value & $0.08^{\circ}$ & $0.12^{\circ \circ}$ & $0.11^{\circ \circ}$ & & & \\
\hline Wald Chi2 & & & & $44.02^{\circ}$ & $46.55^{*}$ & $40.03^{\circ}$ \\
\hline Breusch and Pagan LM test for random effects: $p$-value & & & & 0.20 & 0.20 & 0.20 \\
\hline
\end{tabular}

Notes: $* * / * / 0 / 00$ indicate significance at the 1, 5, 10 and 15\% level, respectively. White (1980) heteroscedasticity consistent standard errors are reported between brackets. ${ }^{1}$ 'Better known opponent' refers to matches where individuals already met each other at least three times. ${ }^{2}$ In Model A, the prize differential is measured by the difference of prizes between winning and losing a match plus the option value of further prizes when a contestant plays a semi-final match (i.e. the prize differential between the winner and the loser of the final). In Model B, the option value is weighted by the relative strength of the contestants in the other semi-final match. In Model C, we weigh the option value by the strength of the best player in the other semi-final match. ${ }^{3}$ Tournament characteristics include: category of tournament ( 5 dummies), overall prize money, soil of the court (1 dummy), indoor or outdoor (1 dummy), size (number of players in the tournament), year ( 2 dummies), month (9 dummies). ${ }^{4}$ Player characteristics include: age, number of titles won before the match, number of previous games played in the tournament before the match, share of head-to-head won, player's status ( 1 dummy), final (1 dummy). 
Table A4 (Cont.)

Effects of prizes and heterogeneity on player's performance: Less known opponent (Fixed effects $v s$. Random effects)

\begin{tabular}{|c|c|c|c|c|c|c|}
\hline \multirow[t]{2}{*}{ Dependent variable: Games won by 'less known opponent' ${ }^{1}$} & \multicolumn{3}{|c|}{ Fixed Effects: OLS } & \multicolumn{3}{|c|}{ Random Effects: GLS } \\
\hline & Model A ${ }^{2}$ & Model B & Model C & Model A & Model B & Model C \\
\hline \multirow[t]{2}{*}{ Prize differential $(1,000 \$)$} & 0.003 & 0.006 & 0.005 & 0.006 & $0.015^{*}$ & $0.016^{*}$ \\
\hline & $(0.007)$ & $(0.009)$ & $(0.010)$ & $(0.006)$ & $(0.007)$ & $(0.008)$ \\
\hline \multirow[t]{2}{*}{ Heterogeneity (difference in players' ranks) } & $-0.008 *$ & $-0.008 *$ & $-0.008 *$ & $-0.007 *$ & $-0.007 *$ & $-0.007^{*}$ \\
\hline & $(0.004)$ & $(0.004)$ & $(0.004)$ & $(0.003)$ & $(0.003)$ & $(0.003)$ \\
\hline Tournament characteristics $^{3}$ & Yes & Yes & Yes & Yes & Yes & Yes \\
\hline Player characteristics ${ }^{4}$ & Yes & Yes & Yes & Yes & Yes & Yes \\
\hline \multirow[t]{2}{*}{ Constant } & 4.06 & 3.06 & 3.20 & $12.81 * *$ & $10.65 * *$ & $10.05 * *$ \\
\hline & $(7.45)$ & $(7.14)$ & $(7.48)$ & $(4.03)$ & $(3.44)$ & $(3.63)$ \\
\hline $\mathrm{N}$ & 608 & 608 & 608 & 608 & 608 & 608 \\
\hline Adj. $R^{2}$ & 0.14 & 0.14 & 0.14 & 0.12 & 0.13 & 0.14 \\
\hline F-stat & $2.38 * *$ & $2.39 * *$ & $2.39 * *$ & & & \\
\hline F-test for significance of individual fixed effects: $p$-value & $0.00 * *$ & $0.01 * *$ & $0.01 * *$ & & & \\
\hline Wald Chi2 & & & & $74.89 * *$ & $79.76 * *$ & $80.87 * *$ \\
\hline Breusch and Pagan LM test for random effects: p-value & & & & 0.30 & 0.29 & 0.29 \\
\hline
\end{tabular}

Notes: $* * / * / 0$ indicate significance at the 1,5 and $10 \%$ level, respectively. White (1980) heteroscedasticity consistent standard errors are reported between brackets. ${ }^{1}$ 'Less known opponent' refers to matches where individuals already met each other a maximum of two times. ${ }^{2}$ In Model A, the prize differential is measured by the difference of prizes between winning and losing a match plus the option value of further prizes when a contestant plays a semi-final match (i.e. the prize differential between the winner and the loser of the final). In Model B, the option value is weighted by the relative strength of the contestants in the other semi-final match. In Model C, we weigh the option value by the strength of the best player in the other semi-final match. ${ }^{3}$ Tournament characteristics include: category of tournament ( 5 dummies), overall prize money, soil of the court (1 dummy), indoor or outdoor (1 dummy), size (number of players in the tournament), year ( 2 dummies), month (9 dummies). ${ }^{4}$ Player characteristics include: age, number of titles won before the match, number of previous games played in the tournament before the match, share of head-to-head won, player's status ( 1 dummy), final (1 dummy). 
Table A5

Effects of ranking-points differential on player's performance

Ranking-points differential

Heterogeneity

Tournament characteristics

Player characteristics ${ }^{3}$

Individual fixed effects

Constant

Adj. $R^{2}$

F-stat

F-test for fixed effects: $p$-value

Wald Chi2

Breusch and Pagan LM test for random

effects: p-value

Notes: $* * / * / 0$ indicate significance at the 1,5 and $10 \%$ level, respectively. White (1980) heteroscedasticity consistent standard errors are reported between brackets. ${ }^{1}$ In Model A, the ranking-points differential is measured by the difference of ranking-points to win between winning and losing a match plus the option value of further points when a contestant plays a semi-final match (i.e. the ranking-points differential between the winner and the loser of the final). In Model B, the option value is weighted by the relative strength of the contestants in the other semi-final match. In Model C, we weigh the option value by the strength of the best player in the other semi-final match. ${ }^{2}$ Tournament characteristics include: category of tournament (5 dummies), overall prize money, soil of the court ( 1 dummy), indoor or outdoor ( 1 dummy), size (number of players in the tournament), year ( 2 dummies), month (9 dummies). ${ }^{3}$ Player characteristics include: age, number of titles won before the match, number of previous games played in the tournament before the match, share of head-to-head won, player's status (1 dummy), final ( 1 dummy) 
Table A6

Effects of prize spread (Ps) interacted with ranking-points differential (Rd) on player's performance

Ps x Rd

Heterogeneity

Tournament characteristics ${ }^{2}$

Player characteristics ${ }^{3}$

Individual fixed effects

Constant

Adj. R ${ }^{2}$

F-stat

F-test for significance of individual

fixed effects: $p$-value

Wald Chi2

Breusch and Pagan LM test for

random effects: $\mathrm{p}$-value Model A, the prize (ranking-points) differential is measured by the difference of prizes (points) between winning and losing a match plus the option value of further prizes (points) when a contestant plays a semi-final match (i.e. the prize (points) differential between the winner and the loser of the final). In Model B, the option value is weighted by the relative strength of the contestants in the other semi-final match. In Model C, we weigh the option value by the strength of the best player in the other semi-final match.

2 Tournament characteristics include: category of tournament ( 5 dummies), overall prize money, soil of the court ( 1 dummy), indoor or outdoor ( 1 dummy), size (number of players in the tournament), year ( 2 dummies), month ( 9 dummies). ${ }^{3}$ Player characteristics include: age, number of titles won before the match, number of previous games played in the tournament before the match, share of head-to-head won, player's status (1 dummy), final (1 dummy). 
Table A7

Effects of prizes and heterogeneity on player's performance: Finals

Prize differential (1,000 \$)

\begin{tabular}{|c|c|c|c|c|c|c|c|c|}
\hline \multicolumn{3}{|c|}{ OLS } & \multicolumn{3}{|c|}{ Fixed Effects: OLS } & \multicolumn{3}{|c|}{ Random Effects: GLS } \\
\hline-0.005 & -0.002 & -0.003 & -0.013 & -0.009 & -0.008 & -0.010 & -0.007 & -0.004 \\
\hline$(0.015)$ & $(0.015)$ & $(0.015)$ & $(0.019)$ & $(0.016)$ & $(0.018)$ & $(0.015)$ & $(0.015)$ & $(0.015)$ \\
\hline$-0.010^{*}$ & & & -0.003 & & & $-0.008^{*}$ & & \\
\hline$(0.004)$ & & & $(0.004)$ & & & $(0.004)$ & & \\
\hline & 0.839 & & & $2.450^{*}$ & & & 1.313 & \\
\hline & $(0.870)$ & & & $(1.272)$ & & & $(0.875)$ & \\
\hline & 0.911 & & & $2.626^{*}$ & & & 1.467 & \\
\hline & $(0.933)$ & & & $(1.347)$ & & & $(0.946)$ & \\
\hline & -0.829 & & & 0.449 & & & -0.515 & \\
\hline & $(1.016)$ & & & $(1.355)$ & & & $(1.003)$ & \\
\hline & $-1.678^{\circ}$ & & & 1.529 & & & -0.965 & \\
\hline & $(1.065)$ & & & $(1.692)$ & & & $(1.085)$ & \\
\hline & $-2.474^{\circ}$ & & & -0.989 & & & $-2.183^{\circ}$ & \\
\hline & $(1.447)$ & & & $(2.111)$ & & & $(1.473)$ & \\
\hline & & $0.736^{* *}$ & & & $0.510 * *$ & & & $0.698 * *$ \\
\hline & & $(0.150)$ & & & $(0.176)$ & & & $(0.143)$ \\
\hline Yes & Yes & Yes & Yes & Yes & Yes & Yes & Yes & Yes \\
\hline Yes & Yes & Yes & Yes & Yes & Yes & Yes & Yes & Yes \\
\hline $11.09^{*}$ & $10.58 *$ & $11.57 *$ & -4.21 & -11.38 & -2.41 & $13.64 *$ & $11.47 *$ & $12.96^{*}$ \\
\hline$(5.34)$ & $(5.53)$ & $(5.29)$ & (17.16) & (17.76) & (17.27) & $(5.53)$ & (5.69) & $(5.40)$ \\
\hline 337 & 337 & 337 & 337 & 337 & 337 & 337 & 337 & 337 \\
\hline 0.03 & 0.06 & 0.08 & 0.14 & 0.19 & 0.17 & 0.09 & 0.13 & 0.19 \\
\hline \multirow[t]{4}{*}{$1.40^{\circ}$} & $1.60^{*}$ & $2.04 * *$ & $1.84 * *$ & $1.95^{* *}$ & $1.93 * *$ & & & \\
\hline & & & $0.04 *$ & $0.02 *$ & $0.05^{*}$ & & & \\
\hline & & & & & & $49.06 * *$ & $59.08 * *$ & $64.50 * *$ \\
\hline & & & & & & 0.82 & 0.88 & 0.90 \\
\hline
\end{tabular}

